\title{
Prevalence and Molecular Epidemiology of Human Papillomavirus in Ecuadorian Women with Cervical Cytological Abnormalities
}

Guido Silva1, Francisco Altamirano ${ }^{2}$, Walter Montenegro ${ }^{2}$ and Ricardo Silva ${ }^{* 1,3,4}$

${ }^{1}$ School of Chemical Sciences at University of Guayaquil

${ }^{2}$ Molecular Biology Department at Teodoro Maldonado Carbo Hospital, Guayaquil, Ecuador

${ }^{3}$ Secretariat for Higher Education, Science, Technology and Innovation (Senescyt), Ecuador

${ }^{4}$ Imbabura Territorial Technical Institute at Yachay, Ecuador

\begin{abstract}
The relationship between human papillomavirus (HPV) and cervical cancer remains a topic of extensive research. This virus is responsible for mild and severe abnormalities that can slowly trigger some type of carcinoma with a strong association with sexual practice. Availability of new techniques for HPV tipification allow to better establish more common virus types associated to this neoplasia. The article presents prevalence and molecular epidemiology (PCR results) from 1000 female patients affiliated to the Ecuadorian Institute of Social Security (IESS), concurrent to Teodoro Maldonado Carbo Hospital in the city of Guayaquil, Ecuador, from July 2011 to August 2013. Results prove that the most prevalent types of HPV present are: HPV-16 (29, 77\%); HPV-52 (16, 18\%); HPV-51 (12, 30\%); HPV-6 (9, 71\%); and HPV-59 (8, 74\%). Molecular epidemiology is quite distinct from that found in other parts of the world. Ecuador is importing Papillomavirus vaccines, and general idea from health authorities is that these vaccines offer protection against $75 \%$ of papilloma virus infections. Results presented in this study, suggest that this protection is less than $30 \%$ for women in the province of Guayas.
\end{abstract}

Keywords: Human Papilloma Virus; HPV; Prevalence; Genotyping; Guayaquil; Ecuador

\section{Introduction}

Human Papillomavirus (HPV) is a group of over 100 related viruses, differentiated from each other by the L1 portion within its genome [1]. Each variety of HPV is assigned a number depending on the order of how they were discovered; classified according to the relationship presented against the development of invasive cervical carcinomas in Human Papillomavirus high risk and low risk [2].

Virtually all cervical cancers are caused by HPV infections, and especially two types, number 16 and number 18 , are considered to be responsible for almost $70 \%$ of all known cases [3]. According to GLOBOCAN [4], cervical cancer is the fourth most common cancer in women, and the seventh overall, with an estimated 528,000 new cases in 2012 and an estimate of 83,000 new cases in WHO Americas region (PAHO). Infection with high-risk HPV represents about $5 \%$ of all cancers in the world [5]. $80 \%$ of these cases are reported today in lowincome countries, where virtually no access to screening, timely control and adequate treatment for those suffering from this disease [4].

According to GLOBOCAN study [4], prevalence of HPV in uterine carcinomas is reported in more than $93 \%$ of tumours, identifying 25 different genotypes of the virus. The study suggests that $5 \%$ or less of cervical cancers is probably true tumours that do not involve direct relationship with the virus. In Ecuador, according to INEC (National Institute of Statistics and Census, 2010), every year about 1,200 new cases of HPV are reported and about 300 women die from uterine carcinomas related to HPV.

According to „PubMed“ search performed January 15, 2014, there are 13 published studies involving HPV in Ecuador, six of those publications were considered relevant for our research [6-11]. From the aforementioned, only one study linked the incidence of HPV with its genotype [9]. The project was led by the National Cancer Institute of Italy, but without removing relevance to the study, the sampled universe is very low (31 HPV positive cases) and does not lead to an evaluative conclusion.
It is our current understanding that viral incidence may vary from region to region, and some authors argue that the frequency of genotypes has changed [5,12-14]. In 2006, HPV-16 and HPV-18 were found as the most frequent types worldwide [15]. In the region of Central-South America, most prevalent types of HPV in cervical cancer in 2006 are presented in Table 1. Today in Italy, the most frequent HPV types are as follow: HPV-16, HPV-31, HPV-18 and HPV-56, with significant differences in HPV genotype distribution according to centres [13]. It is therefore fundamental to know the actual prevalence of HPV in Ecuador [16,17].

\section{Methods}

1000 samples of cervical scraping from female patients mean age 41,01 years, standard deviation (SD) 13 years, range 18 through 55 years of age, presenting cytological abnormalities and attending cytological screening, concurrent to Teodoro Maldonado Carbo Hospital (TMCH) in the City of Guayaquil. TMCH is Guayaquil's, South District reference hospital and receives patients from the whole province of Guayas. Figure 1 presents a cluster graph showing the approximate location of the patient group with respect to the Province of Guayas.

All the specimens were tested for HPV, by PCR techniques in the hospital's Molecular Biology laboratory, July 2011 through October 2013. Target DNA amplification using Real Time GeneAmp PCR

*Corresponding author: Ricardo Silva, School of Chemical Sciences at University of Guayaquil, Ecuador, Tel: 68754799; Fax: 456332; E-mail: raicardo@gmail.com

Received June 20, 2015; Accepted July 15, 2015; Published July 23, 2015

Citation: Silva G, Altamirano F, Montenegro W, Silva R (2015) Prevalence and Molecular Epidemiology of Human Papillomavirus in Ecuadorian Women with Cervical Cytological Abnormalities. J Data Mining Genomics Proteomics 6: 174. doi:10.4172/2153-0602.1000174

Copyright: ( 2015 Silva G, et al. This is an open-access article distributed unde the terms of the Creative Commons Attribution License, which permits unrestricted use, distribution, and reproduction in any medium, provided the original author and source are credited. 
Citation: Silva G, Altamirano F, Montenegro W, Silva R (2015) Prevalence and Molecular Epidemiology of Human Papillomavirus in Ecuadorian Women with Cervical Cytological Abnormalities. J Data Mining Genomics Proteomics 6: 174. doi:10.4172/2153-0602.1000174

\begin{tabular}{|c|c|}
\hline HPV Type & $\%$ \\
\hline 16 & 57.0 \\
\hline 18 & 12.6 \\
\hline 31 & 7.4 \\
\hline 45 & 6.8 \\
\hline 33 & 4.3 \\
\hline
\end{tabular}

Table 1: Prevalence of the most common types of human papillomavirus (HPV) in cervical cancer for the region of Central-South America in 2006 [15].
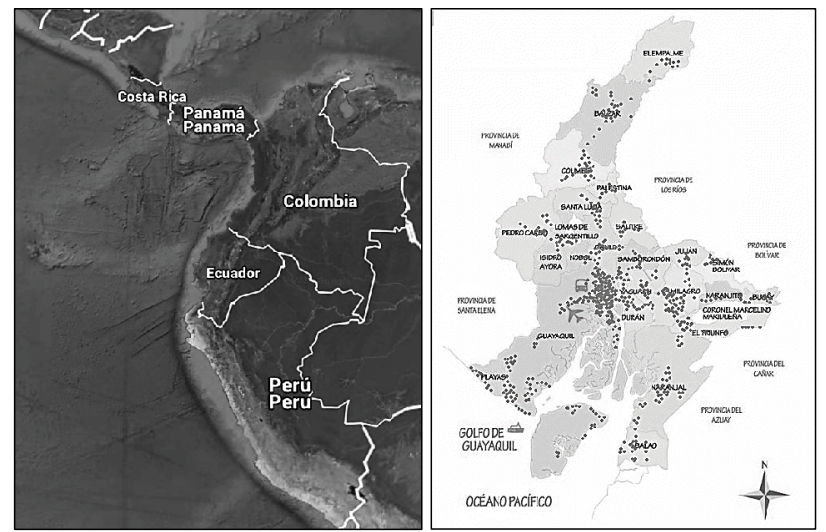

Figure 1: Left Panel presents the area of study (Guayas Province) in relation to the Country of Ecuador. Right Panel presents the political map for Guayas Province and dot clusters corresponding to the approximate place of origin from sample patients.

System 9700 thermocycler (Applied Biosystems ${ }^{\mathrm{Tw}}$ ) and genotyping using labelled oligonucleotide probes (Roche ${ }^{\mathrm{Tt}}$ Linear Array HPV test ${ }^{\circledR}$ ) were utilized.

Cervical cells obtained by the gynaecologist were preserved in $\mathrm{COBAS}^{\bullet}$ or PreseryCyt $\mathrm{t}^{\circ}$ medium, under refrigeration at 2 to $8^{\circ} \mathrm{C}$ for a maximum of 12 weeks. AmpliLute extraction kit contains a quantity of reagent sufficient for 50 tests. LINEAR ARRAY detection kit contains reagents for 96 tests and detects thirty seven genotypes of HPV DNA. Each LINEAR ARRAY HPV genotyping test can process 4 sets of 12 determinations. Each series of tests can include a maximum of 22 samples of cervical scraping leaving two wells for positive and negative controls, totalling 24 samples.

The amplification reagents are packaged with a capacity for 12 tests, however the negative and positive controls are in single-use vials. On the other hand the test strips are airtight and sealed bearings for up to 12 tests. Efficient use of the reagents is in multiples of twelve. In the Hospital test runs were stored until all 22 samples were completed for analysis.

LINEAR ARRAY detection kit detects thirty seven anogenital HPV DNA genotypes $(6,11,16,18,26,31,33,35,39,40,42,45,51,52,53$, $54,55,56,58,59,61,62,64,66,67,68,69,70,71,72,73$ (MM9), 81, 82 (MM4), 83 (MM7), 84 (MM8), IS39 and CP6108 (high-risk in bold)]. HPV types $16,18,31,33,35,39,45,51,52,56,58,59,68,73$ and 82 are defined high-risk (HR) HPV types; HPV-26, 53 and 66 are considered as probable high-risk (PHR), whereas the other genotypes are defined low-risk (LR) HPVs [5].

\section{Results}

Overall, 352 of the 1000 women (35.20\%) were positive for any type of HPV. 43 (4.3\%) could not be genotyped because they did not match any of the specific probes of the strips (uncharacterized genotype); thus HPV genotyping was available for 309 women. HPV cases measured in single and multiple infections, totalized 500 positive ID's. Out of the HPV positive patients, $80(22,73 \%)$ tested positive for cancer. There were no cancer patients in the HPV negative group. Out of 309 infections, 196 (61.80\%) were sustained by a single genotype and 113 (22.60\%) by multiple HPV genotypes (ranging from 2 to 8 ). Genotypes distribution in single and multiple infections is shown in Table 2.

The five most common types of HPV infections detected overall where: HPV-16 in 92 cases (29, $77 \%$ ); HPV-52 in 50 cases (16, $18 \%$ ); HPV-51 in 38 cases (12, $30 \%$ ); HPV-6 in 30 cases (9, $71 \%$ ); and HPV59 in 27 cases $(8,74 \%)$. Prevalence frequency is presented in Figure 2.

In the case of positive cancer patients, the five most common types of HPV infections detected are shown (percentage is computed with respect to the total number of positive cancer patients): HPV-16 in 58 cases (45, 31\%); HPV-59 in 14 cases (10, $94 \%$ ); HPV-18 in 12 cases (9, $38 \%)$; HPV-52 in 12 cases (9, $38 \%)$; and HPV-6 in 6 cases $(4,69$ $\%)$. Prevalence frequency with respect to positive cancer patients is presented in Figure 3.

\begin{tabular}{|c|c|c|c|c|c|c|}
\hline Genotype & $\begin{array}{c}\text { Single } \\
\text { Infection }\end{array}$ & Single \% & $\begin{array}{l}\text { Multiple } \\
\text { Infection }\end{array}$ & $\begin{array}{c}\text { Multiple } \\
\%\end{array}$ & Total & Total $\%$ \\
\hline 6 & 20 & 4.00 & 10 & 2.00 & 30 & 6.00 \\
\hline 9 & 1 & 0.20 & 0 & 0.00 & 1 & 0.20 \\
\hline 11 & 1 & 0.20 & 0 & 0.00 & 1 & 0.20 \\
\hline 16 & 59 & 11.80 & 33 & 6.60 & 92 & 18.40 \\
\hline 18 & 13 & 2.60 & 11 & 2.20 & 24 & 4.80 \\
\hline 31 & 11 & 2.20 & 6 & 1.20 & 17 & 3.40 \\
\hline 33 & 6 & 1.20 & 7 & 1.40 & 13 & 2.60 \\
\hline 35 & 3 & 0.60 & 2 & 0.40 & 5 & 1.00 \\
\hline 39 & 7 & 1.40 & 1 & 0.20 & 8 & 1.60 \\
\hline 40 & 1 & 0.20 & 2 & 0.40 & 3 & 0.60 \\
\hline 42 & 4 & 0.80 & 2 & 0.40 & 6 & 1.20 \\
\hline 45 & 9 & 1.80 & 5 & 1.00 & 14 & 2.80 \\
\hline 51 & 21 & 4.20 & 17 & 3.40 & 38 & 7.60 \\
\hline 52 & 28 & 5.60 & 22 & 4.40 & 50 & 10.00 \\
\hline 53 & 16 & 3.20 & 9 & 1.80 & 25 & 5.00 \\
\hline 54 & 6 & 1.20 & 10 & 2.00 & 16 & 3.20 \\
\hline 55 & 1 & 0.20 & 3 & 0.60 & 4 & 0.80 \\
\hline 56 & 5 & 1.00 & 0 & 0.00 & 5 & 1.00 \\
\hline 58 & 14 & 2.80 & 8 & 1.60 & 22 & 4.40 \\
\hline 59 & 17 & 3.40 & 10 & 2.00 & 27 & 5.40 \\
\hline 61 & 13 & 2.60 & 11 & 2.20 & 24 & 4.80 \\
\hline 62 & 12 & 2.40 & 3 & 0.60 & 15 & 3.00 \\
\hline 66 & 5 & 1.00 & 5 & 1.00 & 10 & 2.00 \\
\hline 67 & 2 & 0.40 & 1 & 0.20 & 3 & 0.60 \\
\hline 68 & 3 & 0.60 & 0 & 0.00 & 3 & 0.60 \\
\hline 69 & 1 & 0.20 & 0 & 0.00 & 1 & 0.20 \\
\hline 70 & 3 & 0.60 & 2 & 0.40 & 5 & 1.00 \\
\hline 71 & 3 & 0.60 & 0 & 0.00 & 3 & 0.60 \\
\hline 72 & 5 & 1.00 & 2 & 0.40 & 7 & 1.40 \\
\hline 73 & 4 & 0.80 & 0 & 0.00 & 4 & 0.80 \\
\hline 81 & 5 & 1.00 & 0 & 0.00 & 5 & 1.00 \\
\hline 83 & 3 & 0.60 & 3 & 0.60 & 6 & 1.20 \\
\hline 84 & 4 & 0.80 & 5 & 1.00 & 9 & 1.80 \\
\hline CP6108 & 2 & 0.40 & 1 & 0.20 & 3 & 0.60 \\
\hline IS39 & 1 & 0.20 & 0 & 0.00 & 1 & 0.20 \\
\hline Total & 309 & 61.80 & 191 & 38.20 & 500 & 100 \\
\hline
\end{tabular}

Table 2: Human Papilloma Virus (HPV) genotyping of single or multiple infections in 309 women with detectable HPV DNA. Percentage is calculated with respect to totalized 500 positive HPV ID's. 


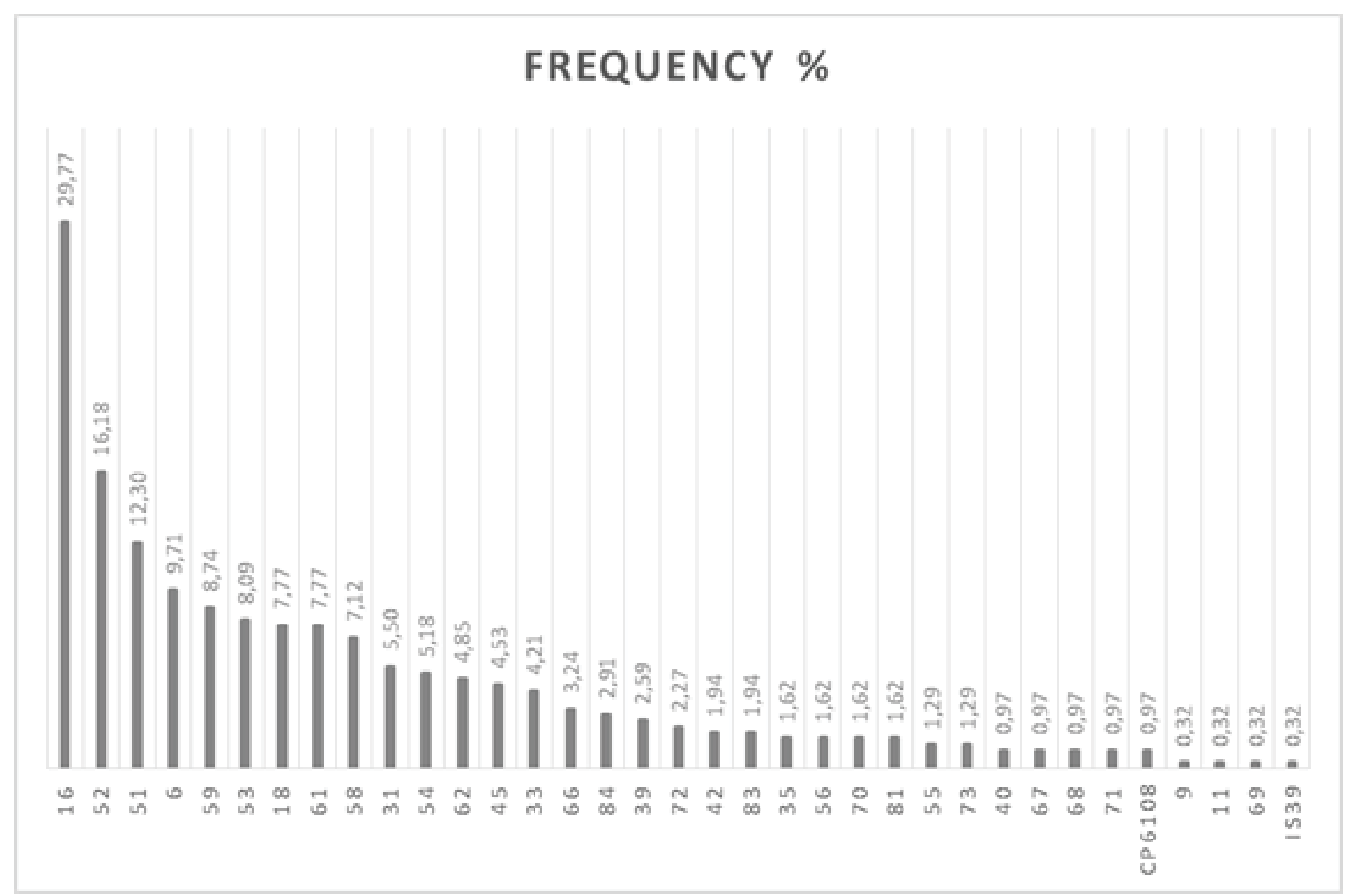

Figure 2: Genotype Frequency percentage with respect to totalized positive HPV ID's.

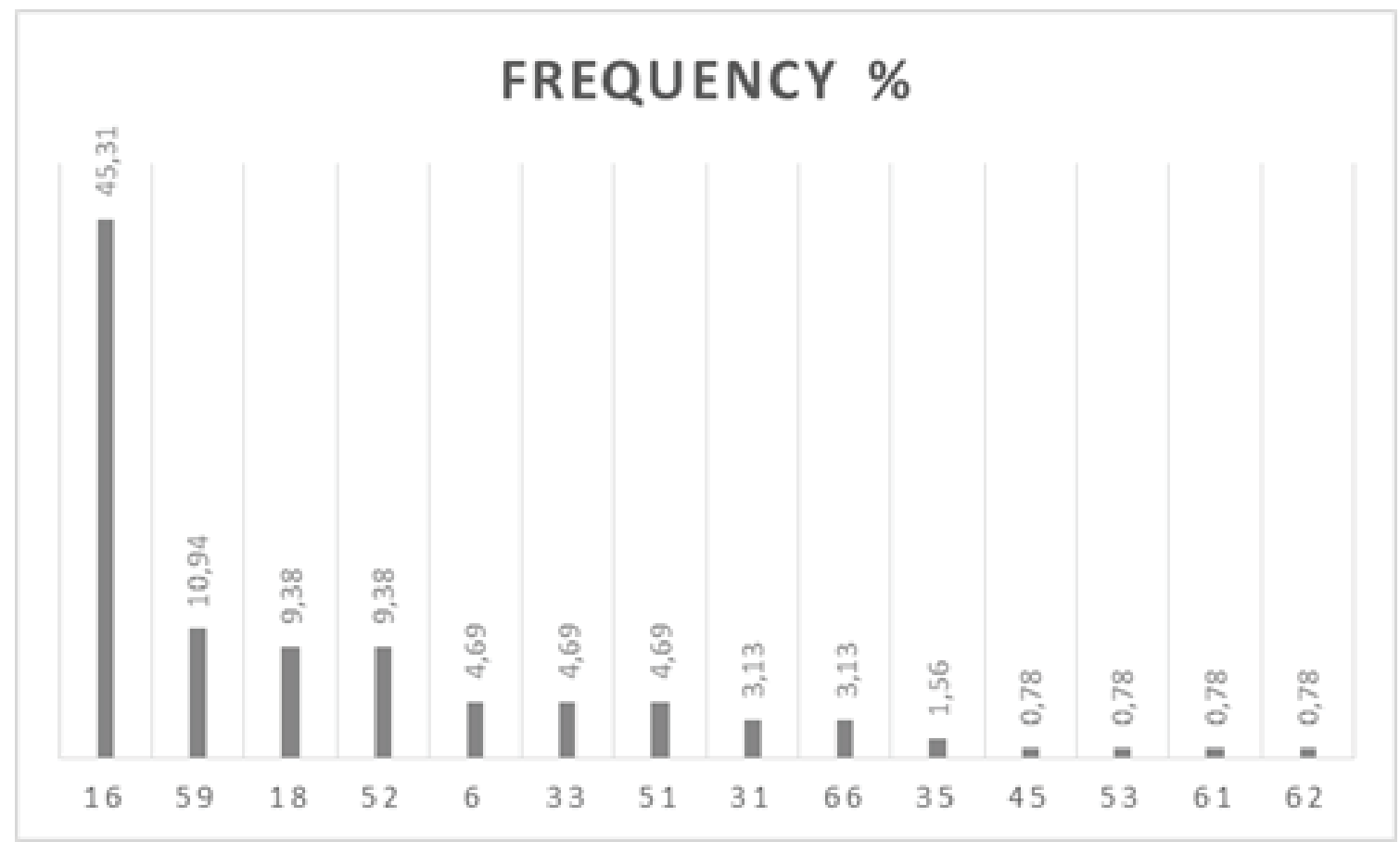

Figure 3: Genotype Frequency percentage with respect to positive cancer patients HPV ID's. 
Citation: Silva G, Altamirano F, Montenegro W, Silva R (2015) Prevalence and Molecular Epidemiology of Human Papillomavirus in Ecuadorian Women with Cervical Cytological Abnormalities. J Data Mining Genomics Proteomics 6: 174. doi:10.4172/2153-0602.1000174

\section{Discussion and Conclusions}

Disturbing is the extent of Human Papillomavirus infection, not only in Ecuador, but in the rest of the world. Cervical cancer remains, the second cause of national and global death from malignancy in women. Incidence computed in this article is not encouraging: the viral strains that most often infect women in the sample are oncogenic types (HR), in particular, the dreaded HPV16. From the overall sample, HRHPV corresponds to 331 cases (66, $2 \%)$; LR-HPV, 134 cases $(26,8 \%)$ and PHR-HPV, 35 cases (7 \%).

Among the positive cases found 80 patients who developed invasive uterine carcinomas, i.e., $100 \%$ of infected papilloma patients, $23.86 \%$ developed Cervical Cancer. These patients were mostly infected by High Risk Virus (see Figure 3). If we assume that most prevalent types of HPV in cervical cancer in 2006 for the region (Table 1) were the same as in Ecuador, then is evident, that there has been a shift in the epidemiological profile, furthermore, in positive cancer patients the prevalence is also different, as can be seen in Table 3 .

If we compare our results with other papers related to the prevalence of HPV in Ecuador, we will not find many differences. HPV 16 is still dominant. But, when compared with results from other countries in cancer positive patients, the differences are clear (Table 4). The genotype 16 is dominant, however relative frequency varies and other phenotypes differ significantly. Notice that HPV 18 is absent from both Ecuadorian results.

The only two vaccines approved by the FDA to treat HPV infection, Gardasil $^{\circ}$ and Cervarix ${ }^{\diamond}$ were created to fight HPV-16 and HPV-18 genotypes (its action was also demonstrated against genotypes 6, 11, 45,33 and 31). From Table 3, HPV-16 remains the most common HPV strain, HPV-18 appears as the third most common strain for patients with cervical cancer, confirming its oncogenic capacity, but it's absent from the general categorization.

Ecuador is importing Papillomavirus vaccines, spending around $6,943,792$ U.S. dollars annually. General idea from health authorities

\begin{tabular}{|c|c|c|c|c|c|}
\hline $\begin{array}{c}\text { HPV Type } \\
\mathbf{2 0 0 6}\end{array}$ & $\mathbf{\%}$ & $\begin{array}{c}\text { HPV Type } \\
\mathbf{2 0 1 4}\end{array}$ & $\mathbf{\%}$ & HPV + C 2014 & \% \\
\hline 16 & 57.0 & $\mathbf{1 6}$ & 29,77 & $\mathbf{1 6}$ & 72,50 \\
\hline 18 & 12.6 & $\mathbf{5 2}$ & 16,18 & $\mathbf{5 9}$ & 17,50 \\
\hline 31 & 7.4 & $\mathbf{5 1}$ & 12,30 & $\mathbf{1 8}$ & 15,00 \\
\hline 45 & 6.8 & $\mathbf{6}$ & 9,71 & $\mathbf{5 2}$ & 15,00 \\
\hline 33 & 4.3 & $\mathbf{5 9}$ & 8,74 & $\mathbf{6}$ & 7,50 \\
\hline
\end{tabular}

Table 3: Comparison of the most common types of human papillomavirus (HPV) in cervical cancer, Column 1 and 2 are taken from Table 1[15]; Column 3 and 4 represent most prevalent strains from this study; Column 5 and 6 represent most prevalent strains in positive cancer patients.

\begin{tabular}{|c|c|c|c|c|c|c|c|}
\hline \multicolumn{2}{|c|}{$\begin{array}{c}\text { Frequency \% } \\
\text { (High Risk) (2014) }\end{array}$} & \multicolumn{2}{|c|}{$\begin{array}{c}\text { Study in Ecuador } \\
(2009) \\
\text { Leon M [9] }\end{array}$} & \multicolumn{2}{|c|}{$\begin{array}{l}\text { Study in Spain } \\
\qquad(2012) \\
\text { Sánchez E [11] }\end{array}$} & \multicolumn{2}{|c|}{$\begin{array}{c}\text { Study in } \\
\text { Argentina } \\
(2005) \\
\text { Marín H }\end{array}$} \\
\hline \multicolumn{2}{|c|}{$\begin{array}{l}352 \text { positive } \\
\text { samples }\end{array}$} & \multicolumn{2}{|c|}{43 positive samples } & \multicolumn{2}{|c|}{111 positive samples } & \multicolumn{2}{|c|}{$\begin{array}{l}63 \text { positive } \\
\text { samples }\end{array}$} \\
\hline HPV & $\%$ & HPV & $\%$ & HPV & $\%$ & HPV & $\%$ \\
\hline 16 & $29.7 \%$ & 16 & $16.3 \%$ & 16 & $51.4 \%$ & 16 & $25.9 \%$ \\
\hline 52 & $16.2 \%$ & 59 & $11.6 \%$ & 18 & $3.7 \%$ & 18 & $14.2 \%$ \\
\hline 51 & $12.3 \%$ & 31 & $9.3 \%$ & 45 & $3.7 \%$ & 58 & $14.2 \%$ \\
\hline 6 & $9.7 \%$ & 39 & $9.3 \%$ & 33 & $5.5 \%$ & 53 & $4.7 \%$ \\
\hline 59 & $8.7 \%$ & 58 & $9.3 \%$ & 56 & $1.8 \%$ & 31 & $3.2 \%$ \\
\hline
\end{tabular}

Table 4: Comparing our results with other results from different studies. 5 more prevalent HPV Types. is that these vaccines offer protection against $75 \%$ of papilloma virus infections. Results presented in this study, suggest that this protection is less than $30 \%$ for women in the province of Guayas. That is, we are well below expectations. Even the 9-valent human papillomavirus (HPV) vaccine (HPVs 6/11/16/18/31/33/45/52/58) being researched [14] will not significantly reduce the risk of infection for Guayaquilean women, therefore, a specific line of research should be initiated so that Ecuador can able to protect its female population from local prevalent HPV strains.

\section{Acknowledgment}

Dr. Ricardo Silva was member of the Prometeo Program, sponsored by the Secretariat for Higher Education, Science, Technology and Innovation (Senescyt) in the Republic of Ecuador. This research was supported by the Molecular Biology Department at Teodoro Maldonado Carbo Hospital, Guayaquil, Ecuador and by the Ecuadorian Institute for Social Security (IEES).

Researchers did not receive any type of support or sponsorship from the technology manufacturers. Senescyt did not provide additional support for the development of this research. Experiments were performed independently and the authors of the article in no way altered or modified the measured results.

\section{References}

1. Ken SR, Michael AP, Patrick RM (2009) Microbiología Médica (6th edition) Elsevier, Barcelona, Spain.

2. American Cancer Society (2014) Human Papillomavirus (HPV, Cancer, HPV testing and HPV vaccines.

3. CDC (2010) National and state vaccination coverage among adolescents aged 13 through 17 years-United States. Centres for Disease Control and Prevention, Atlanta, Morbidity and Mortality Weekly Report (MMWR) 201160 : 1117-1123.

4. Soerjomataram I, Ervik M, Dikshit R, Eser S, Mathers C, et al. (2013) GLOBOCAN 2012 v1.0, Cancer Incidence and Mortality Worldwide: IARC Cancer Base No. 11

5. Roberta P, Marcello C, Antonella U, Giuseppina M, Angelo M, et al. (2014) Prevalence and molecular epidemiology of human papillomavirus Infection. Journal of Public Health Research 3: 21-26.

6. Ocampo L, Narváez R, Narváez L, Paz-y-Miño C (1992) Chromosome fragility in lymphocytes of women with cervical uterine lesions produced by human papillomavirus. Cancer Genet Cytogenet 59: 173-176.

7. Konno R, Yaegashi N, Matsunaga G, Araujo I, Corral F, et al. (1996) Prevalence of HPV DNA in cervical lesions in patients from Ecuador and Japan. Tohoku J Exp Med 180: 261-272

8. Buonaguro L, Izzo S, Lopez G, Vega X, Maldonado Reyes CF, et al. (2008) A pilot study on the distribution of human papillomavirus genotypes and HPV-16 variants in cervical neoplastic lesions from Ecuadorian women. J Med Virol 80 1959-1965.

9. Leon ML, Muñoz K, Fagioni A, Amador LG, Frain B, et al. (2009) Human papillomavirus infection and its association with cervical dysplasia in Ecuadorian women attending a private cancer screening clinic. Braz J Med Biol Res 42: 629-636

10. Sánchez D, González-Andrade F (2009) HPV genotyping in anogenital abnormal samples of Ecuadorian women. Cancer Biomark 5: 225-232.

11. Sánchez E (2012) Infección del Virus Papiloma Humano y Cáncer de Cuello Uterino: Distribución de genotipos en mujeres conizadas por lesión escamosa intraepitelial de alto grado (CIN 2-3) y Análisis de los cofactores de Cáncer de Cérvix en Málaga. (Tesis Doctoral). Universidad de M’laga, España.

12. Paganini G, D‘Amico M, Cannone M, Bertuletti C, Barberis MC, et al. (2009) Cervical cancer screening programs in low-income communities. Experiences from Ecuador. Low cost detection of HPV infection in a developing country. Pathologica 101: 76-79.

13. Blas M, Byraiah G, Carcamo C, Brown B, Soohoo M (2013) Cervical HPV Infection in Female Sex Workers: A Global Perspective. Open AIDS J 30: 58 66. 
Citation: Silva G, Altamirano F, Montenegro W, Silva R (2015) Prevalence and Molecular Epidemiology of Human Papillomavirus in Ecuadorian Women with Cervical Cytological Abnormalities. J Data Mining Genomics Proteomics 6: 174. doi:10.4172/2153-0602.1000174

14. De Marco L, Gillio-Tos A, Del Mistro A, Girlando S, Baboci L, et al. (2014) Age and geographic variability of human papillomavirus high-risk genotype distribution in a large unvaccinated population and of vaccination impact on HPV prevalence. J Clin Virol 60: 257-263.

15. Marín H, Lucero R, Schelover E, Deluca G, Gorodner J (2005) Prevalencia de Genotipos de Virus de Papiloma Humno (HPV) en población hospitalaria de la ciudad de Corrientes.
16. Alemany L, Ruiz PA, Tous S, Lima MA, Bruni L et al. (2014) Potential impact of a 9-valent HPV vaccine in HPV-related cervical disease in 4 emerging countries (Brazil, Mexico, India and China). Cancer Epidemiol 38: 748-756.

17. You-Lin Qiao, Xavier C, Xavier Bosch F (2006) The epidemiology of human papillomavirus. International Journal of Gynecology and Obstetrics 94: 8-21. 